\title{
ÁREAS DE ABANDONO \\ ANÁLISE COM BASE NOS FUNDAMENTOS DO DESENHO AMBIENTAL SOBRE PROJETOS QUE VISAM A RECUPERAÇÃO DE TERRITÓRIOS DEGRADADOS
}

\author{
AREAS OF ABANDONMENT \\ ANALYSIS BASED ON DESIGN ENVIRONMENTAL FUNDAMENTS ABOUT \\ PROJECTS AIMED TO RECOVER DEGRADED AREAS
}

TIAGO BRITO DA SILVA

Mestrando em Arquitetura e Urbanismo pela FAU-USP. Arquiteto Urbanista pela

Universidade Estadual de Campinas.

e-mail: tiagobritoarq@gmail.com

\begin{abstract}
RESUMO
O processo de desindustrialização de vastas áreas urbanas, que vem acontecendo em diversas cidades pelo mundo, tem papel fundamental no surgimento de áreas abandonadas, inclusive em regiões centrais do território destas cidades.

Estruturas obsoletas, que foram abandonadas pela sociedade na qual estavam inseridas, abrem espaço para a reflexão sobre a relação entre a sociedade e o território que esta habita, constituindo uma importante dimensão do projeto de paisagem.

A análise proposta neste artigo se baseia em recentes esforços teóricos, que tratam da interface entre estas áreas abandonadas e sua vocação no projeto da paisagem, tendo como foco projetos que visam a recuperação de territórios degradados e afetados pela contaminação da ação antrópica.
\end{abstract}

Palavras-chave: Desenho Ambiental; Brownfields; Terrain Vagues; Terceira Paisagem; Parques; Áreas contaminadas. 


\begin{abstract}
The process of deindustrialization of large urban areas, which has been occurring in several cities around the world, plays a fundamental role in the emergence of abandoned areas, including downtown regions of these cities.

Obsolete structures that were abandoned by the society in which they were implanted brings a chance for reflection on the relationship between society and the territory, which is an important dimension of landscape design.

The analysis proposed in this article is based on recent theoretical efforts on the interface between these abandoned areas and their vocation in the landscape design, focusing on projects aimed at the restoration of degraded lands and affected by contamination of human actions.
\end{abstract}

Keywords: Environmental Design; Brownfields; Terrain Vagues; Third Landscape; Parks; Contaminated Areas.

\title{
INTRODUÇÃO
}

O presente artigo tem por objeto a discussão acerca de projetos da paisagem em áreas degradadas, muitas vezes afetadas pela contaminação provocada por processos antrópicos, decorrentes principalmente de processos de desativação da indústria.

Na primeira parte, será feita uma breve análise sobre os processos de formação desses territórios do abandono, que serão denominados "Brownfields". Para embasamento teórico sobre a formação dessas paisagens, foram selecionados dois autores que debatem o assunto: Gilles Clément, que discorre acerca da formação da "Terceira Paisagem", e Ignasi de Solà-Morales, que trata da formação de "Terrains Vagues".

Na segunda parte, será feito um fichamento de projetos da paisagem que tem como foco a recuperação de áreas degradadas, com o objetivo de observar a evolução deste

\footnotetext{
1 Termo formalizado pela Northeast Midwest Congressional Coalition. Será adotado o termo em inglês pois é difundido em diversos países.
} 
tipo de intervenção. Foram elencados cinco projetos internacionais com relevância no tratamento de Brownfields, que são: Gas Works Park e High Line Park nos Estados Unidos, Landschaftspark na Alemanha, Promenade Planté na França e Stratford Olimpic Park na Inglaterra. Na sequência, será feito um paralelo com intervenções correlatas em São Paulo, no qual serão analisados o Parque Villa Lobos, a Praça Victor Cívita e o Parque Orlando Villas Bôas.

Por fim, será feita uma análise da evolução das soluções de projeto para os parques internacionais apresentados para que se possa entender, comparativamente, em que nível se encontram os projetos implantados em São Paulo. Para isso, serão utilizadas como base as teorias de desenho ambiental discutidas por lan L. Mcharg, Michael Hough e Maria de Assunção Ribeiro Franco.

\section{ALTERAÇÕES NO TECIDO URBANO: A formação de áreas abandonadas}

Ao analisar o processo de evolução da metropolização, nota-se que em meados da década de 1970, com o declínio gradual da indústria, diversas cidades passam a ter suas principais atividades econômicas ligadas à prestação de serviços e ao comércio. Segundo Queiroga (2001):

[...] Ao iniciar este século, estamos diante da terceira revolução industrial. Novas tecnologias e novas espacialidades se constroem. A dispersão da produção industrial e o fortalecimento de um terciário superior para além do território metropolitano, constitui, em diversos países, formações megalopolitanas. A perspectiva da razão de dominação, exercida pelas empresas globais, estrutura as principais relações sócio-espaciais de produção do território megalopolitano, subjugando as ações do Estado, dizimando solidariedades locais.

A transição entre a cidade industrial e o período técnico-científico-informacional ${ }^{2}$ deixa marcas claras no território, sendo as áreas abandonados pelo processo de deslocamento da indústria um exemplo claro das alterações do tecido urbano. Pode-se dizer que estas áreas abandonadas são frutos da materialização de uma nova fase do processo de evolução das cidades, onde a dispersão da produção industrial e o fortalecimento do setor terciário são reflexos deste processo.

2 O Meio técnico-científico-informacional é, segundo Santos (2012), uma consequência espacial do período marcado pela globalização da produção e do consumo. 
Fenômeno observado em diversas cidades pelo mundo, estas áreas abandonadas têm como principal característica o fato de serem pontos quase inabitados, instalados em regiões centrais do território urbano. São lugares aparentemente abandonados, onde as memórias do passado se sobrepões ao cenário presente e que são fruto dos mais diversos processos, como o fim de ciclos econômicos, as mudanças de legislação, contaminação, entre outros. ${ }^{3}$

É necessário enfatizar, ainda, que em grandes cidades de países como Alemanha, Bélgica e Estados Unidos, estas zonas de "abandono" contabilizam áreas representativas, chegando a totalizar extensões maiores que a cidade de São Paulo.

\section{CLASSIFICAÇÕES E DEFINIÇÕES}

Esses territórios abandonados em áreas urbanizadas são objeto de estudo de diversos teóricos que debatem sua função ambiental, abrangendo fatores sociais, ecológicos, econômicos e históricos.

Neste artigo, as áreas analisadas serão denominadas "Brownfields"4, que segundo as definições da associação CARBENET ${ }^{5}$, brownfields são territórios que foram afetados por antigos usos e que se encontram deterioradas, abandonadas ou subutilizadas, podendo ter problemas de contaminação do solo e água. A associação destaca que os brownfields são encontrados principalmente em áreas urbanas desenvolvidas e apresentam potencial para reuso, no entanto, necessitam de intervenção para voltar a ser utilizados.

\footnotetext{
${ }^{3}$ Segundo Solá Morales: São lugares degradados nos que somente certos valores residuais parecem se manter apesar de sua completa desafeição da atividade da cidade. São, em definitiva, lugares externos, estranhos, que ficam foram dos circuitos, das estruturas produtivas. Desde um ponto de vista econômico, áreas industriais, estações de trem, portos, áreas residenciais inseguras, lugares contaminados, tem se convertido em áreas das que se pode dizer que a cidade já não se encontra ali.

4 O termo "brownfields" é utilizado desde 1975, o termo foi amplamente difundido em meados da década de 1990 nas áreas do urbanismo e planejamento urbano.

${ }^{5}$ CABERNET (Concerted Action on Brownfield and Economic Regeneration Network) é uma rede europeia de peritos que aborda questões envolvendo a regeneração de "brownfields".
} 
A partir dessa definição, a leitura dos territórios que se propõe neste artigo se baseia nos conceitos de Terrain Vagues, uma categoria de território elaborada por Solà-Morales, e a definição de Terceira Paisagem, classificação definida por Gilles Clément. Nas definições de Terrain Vagues, os territórios abandonados são descritos como áreas indefinidas, ambíguas, vazias, vagas, improdutivas e, em muitos casos, obsoletas, sem delimitações claras de território, fruto de transformações econômicas e sociais. 0 autor cita como exemplos de Terrain Vagues áreas industriais abandonadas, áreas de linhas férreas desativadas ou subutilizadas, espaços residuais, edifícios deteriorados, áreas portuárias caducas pela conteinerização. De modo geral, terrenos definidos como Terrain Vagues são compostos por brownfields, pois na grande maioria dos casos são áreas com certo grau de contaminação.

Ainda segundo Solà-Morales (2002), essas áreas apresentam dupla condição, pois, ao mesmo tempo que remetem ao abandono, elas apresentam qualidades e potencialidades que podem fortalecer novos usos, pois refletem o encontro do presente com o passado, evocando características específicas que constroem uma relação distinta com seu entorno e com a cidade.

Já na teoria proposta por Gilles Clément, o território é classificado como:

- Antropizado - fruto da ocupação e ação humana;

- Conjuntos Primários e Reserva - o lugar não explorado, o meio natural;

- Resíduo - território fruto do abandono de um terreno anteriormente explorado por atividades industriais, agrícolas, urbanas, entre outros;

- Terceira Paisagem - resultado da ação biológica sobre o território residual, sem a interferência humana.

Um diferencial da teoria da Terceira Paisagem é a inclusão dos processos naturais biológicos na formação da paisagem, propondo que territórios abandonados podem ser vistos como refúgios para biodiversidade, fator que agrega valor a locais normalmente negligenciados.

As duas teorias apresentadas são complementares, sendo que uma delas, os Terrain Vagues, explora as condições de áreas de abandono, buscando nos processos sociais, econômicos, físicos e históricos uma resposta para a formação dos territórios, enquanto a outra, a Terceira Paisagem, busca entender os processos que são desen- 
cadeados após a formação destes territórios. Esta complementariedade será utilizada de base para guiar a análise pretendida por este artigo, possibilitando uma leitura de territórios abandonados desde a sua formação até os processos que a sua existência desencadeia e qual a importância desses fatores no momento de se propor intervenções de projeto nessas áreas.

\section{DESENHO AMBIENTAL: Atuação em Brownfields}

Dessa forma, muitos brownfields estão relacionados aos processos históricos do local de sua inserção, configurando Terrain vagues, que não deixam para trás apenas um território degradado, mas abrem novas possibilidades de renovação e até mesmo de formação de áreas que podem servir de reserva futura de áreas livres na cidade, a serem utilizadas em momentos devidos (Donadon, 2009).

Projetos que visam a recuperação destas áreas demandam sensibilidade durante a leitura do território e objetivos que buscam não só elementos de apelo estético, mas intensificam os vínculos com o meio ambiente e exploram as diversas potencialidades do território. Assim como discorre Hough (1995):

Vida urbana separada dos processos naturais é destrutiva e um único uso exclusivo do território é desaproveitoso e insalubre para sobrevivência humana. O território deve ser estudado para seus possíveis múltiplos usos e múltiplos retornos, com o menor esforço aplicado.

Uma linha de projeto que explora estes preceitos é o "Desenho Ambiental", que incorpora a ideia do processo ao projeto, considerando desde a ação antrópica em harmonia com os processos naturais, até a busca pela otimização da preservação e conservação da energia nos sistemas. O desenho ambiental vai além da criação do projeto, buscando entender e direcionar no momento da implantação e durante sua ocupação. Segundo a definição de Franco (2000):

[...] Desenho Ambiental é uma expressão metafórica, mesmo porque o ambiente não se desenha. A semântica da palavra ambiente carrega o sentido de complexidade infinita, logo Desenho Ambiental refere-se a desenho para o ambiente, no qual se supõe que o projeto seja o elemento formulador e indutor de um processo. 
Os processos abordados pelo desenho ambiental buscam um novo estágio de evolução. A tabela elaborada por Mcharg (1994), dá uma clara visão desses processos e é exposta a seguir:

\section{EVOLUÇÃO $\rightarrow$}

\begin{tabular}{c|c} 
Estágio Primitivo & Estágio Avançado \\
\hline Simples & Complexo \\
\hline Uniforme & Diversificado \\
\hline Instável & Estável \\
\hline Baixo número de espécies & Alto número de espécies \\
\hline Baixo número de simbioses & Alto número de simbioses \\
\hline Alta entropia & Baixa entropia \\
\multicolumn{2}{c}{} \\
\end{tabular}

Para analisar estes processos aplicados ao projeto, foram escolhidos os projetos de parques, por abrir espaço para diferentes leituras do território e da sua relação com determinantes biofísicos e sócio culturais. Os parques possibilitam projetos que exploram estes conceitos, pois se apresentam como reserva de território dentro da malha urbana e possibilitam um caminho para entendimento e agregação da terceira paisagem. Também são começo para experimentar novas relações entre o homem e o meio ambiente, em uma busca por sua complexificação em conjunto com a biodiversidade.

Segundo Hough (1995):

Os parques nas últimas décadas foram direcionados, na sua maior parte dos casos, para atividade de recreação e contemplação. Mas a dinâmica da população se alterou e a recreação, uma vez confinada aos parques, passa a ocupar todo território urbano.

Assim, os parques analisados não serão admitidos como elementos isolados do meio urbano, com uma participação muito restrita na sua dinâmica e que se destinam apenas ao lazer, onde o valor estético fica acima do seu potencial como provedor de qualidade ambiental. Pelo contrário, serão considerados como uma ferramenta de aplicação dos conceitos do desenho ambiental, tornando-os uma alternativa potencial para ocupação e recuperação dos brownfields. 


\section{PROJETOS DA PAISAGEM: Uma visão global do tratamento de áreas degradadas}

Diante dos conceitos expostos, pode-se dizer que os brownfields têm grande potencial nos processos de revitalização urbana. Apesar do processo de industrialização, acompanhado de destruição e poluição, existir há mais de trezentos anos, somente na metade do século passado que começaram a despontar esforços e projetos para recuperar os brownfields, a fim de determinar o que é um ambiente equilibrado.

Existem diversas maneiras de se aproveitar este potencial, sendo algumas delas baseadas nos conceitos de Desenho Ambiental. Segundo Hough (1995):

Novos conceitos para nossas definições de desenho urbano precisam ser explorados, com medidas que quebrem antigos paradigmas para assegurar o futuro ambiental e a viabilidade social das cidades.

Para elucidar esta categoria de projetos socioecológicos, a seguir serão apresentados estudos de caso que vislumbram diferentes formas de intervir no espaço urbano e potencializar áreas esquecidas ou abandonadas, em ambientes com ampla ocupação humana.

Para avaliação dos projetos foi considerada a sua relevância e inovação no período em que foram implantados e os fatores que os tornaram projetos modelo. Além disso, considerou-se o reflexo de sua implantação na paisagem existente, levando em consideração seus benefícios ecossistêmicos, incluindo sua relevância para os habitantes de suas redondezas.

A leitura dos projetos foi feita com base em fotos aéreas, que foram delimitadas de modo a expor a relação dos parques com a malha urbana na qual estão inseridos. Também foram analisados os partidos dos projetos, incluindo implantações e detalhes dos mesmos, quando disponíveis. E foram consultados os sites oficiais dos parques ou dos órgãos que os administram para levantar dados sobre sua relação com a comunidade que faz uso desses locais.

Estes estudos de caso são listados a seguir: 


\begin{tabular}{l|l|c}
\multicolumn{1}{l}{ Projeto } & Autor & Ano \\
\hline Gas Works Park & Richard Haag & 1975 \\
\hline Landschaftspark & Latz + Partner & 1991 \\
\hline Promenade Planté & Jacques Vergely e Philippe Mathieux & 1993 \\
\hline High Line Park & $\begin{array}{l}\text { James Corner Field Operations e Diller } \\
\text { Scofidio + Renfro }\end{array}$ & 2009 \\
\hline Queen Elizabeth Olympic Park & EDAW Consortium & 2012 \\
\hline
\end{tabular}

\section{GAS WORKS PARK}

O Parque "Gas Works Park" tem área de 19,1 hectares e está localizado na cidade de Seattle, em Washington nos Estados Unidos. O parque foi implantado na área da antiga sede da "Seattle Gas Company", que esteve em funcionamento entre 1906 e 1956. A propriedade foi adquirida em 1962 pela prefeitura de Seattle, com a finalidade de se tornar uma área pública de lazer. No entanto, a área sofreu processos de contaminação pelas atividades fabris desenvolvidas anteriormente, o que a configurava como um brownfield.

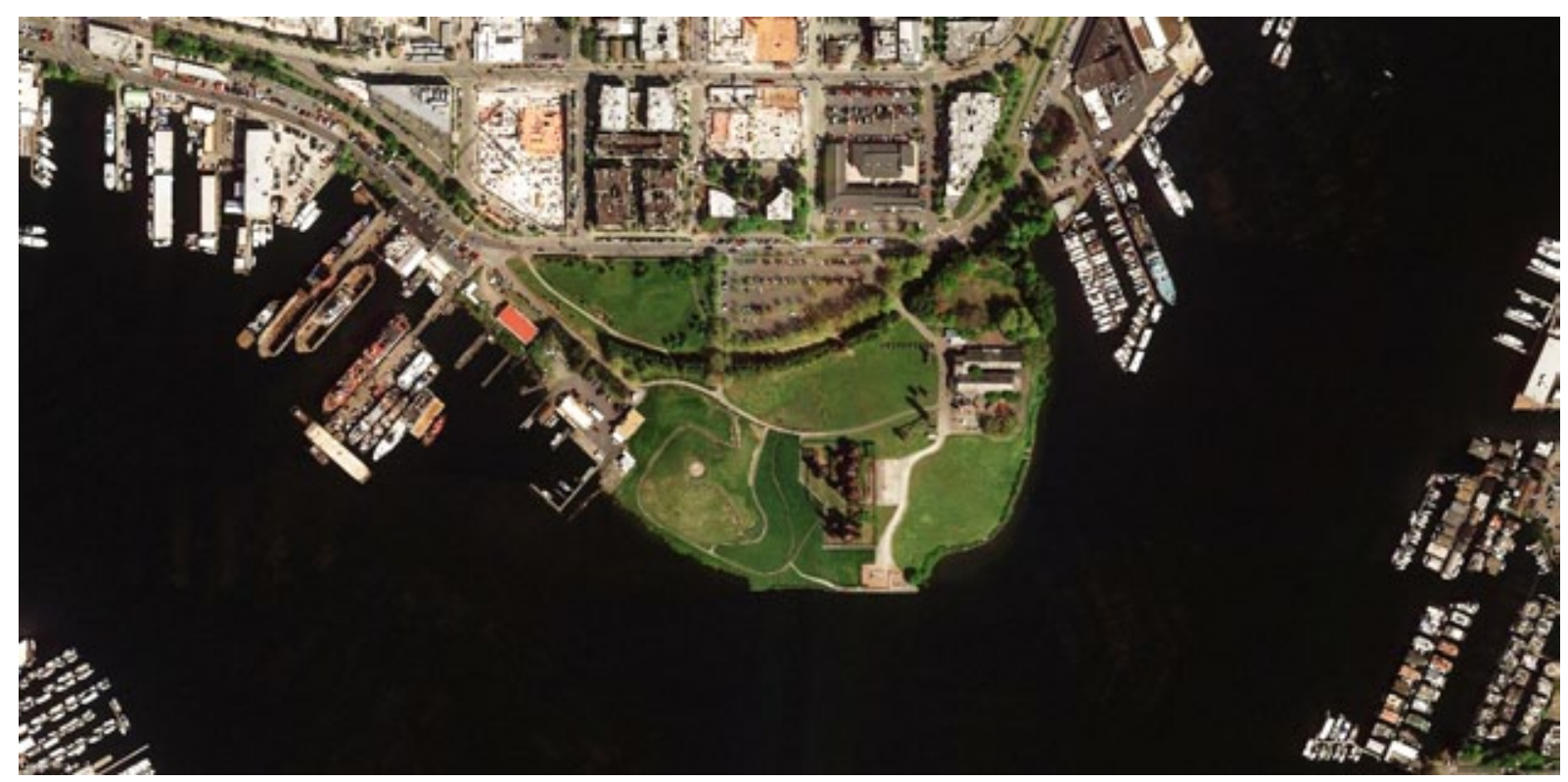

Figura 1 - Vista aérea do Gas Works Park. Fonte: Google Earth 2015 


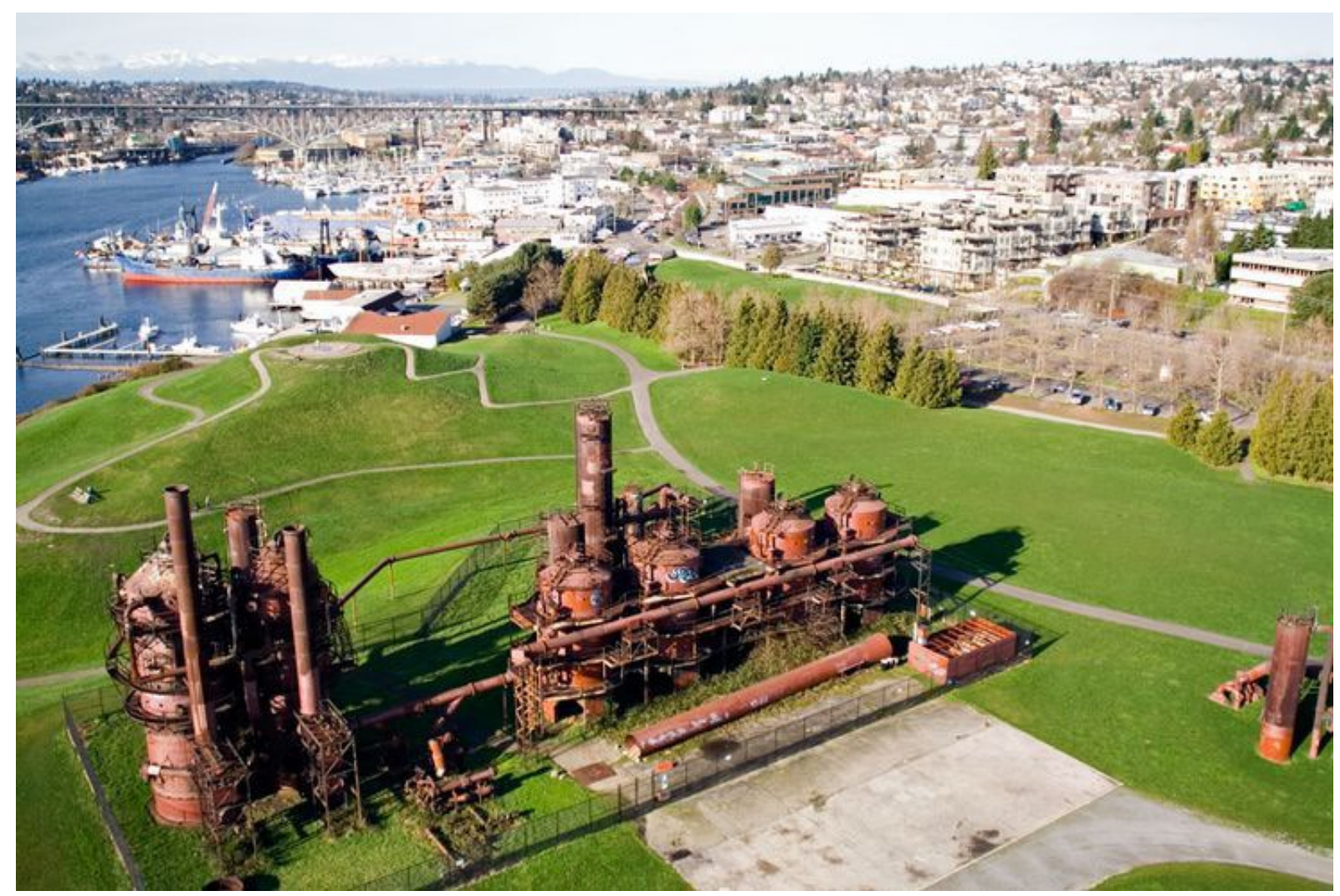

Figura 2 - Vista do Gas Works Park. Fonte: http://hubpages.com/

O projeto do parque, concebido por Richard Haag, foi inovador ao incorporar várias partes da antiga planta industrial no seu projeto. Além disso, o projeto englobou a recuperação dos solos degradados pela antiga fábrica, no qual foram utilizadas enzimas para degradação de óleos e materiais orgânicos para promover o crescimento de microrganismos que fertilizaram o solo, estimulando desse modo a quebra natural de contaminantes.

O projeto possibilitou a retomada por parte da população de uma península esquecida, em uma área portuária. Atualmente, o parque é um dos espaços públicos mais visitados da cidade de Seattle e representa uma retomada das áreas verdes em um território amplamente urbanizado.

No entanto, apesar da sua importância na recuperação de um território contaminado, o projeto não traz biodiversidade para o local, uma vez que a paisagem é composta basicamente por um grande gramado e massas arbóreas isoladas. 


\section{LANDSCHAFTSPARK}

O Landschaftspark é um parque público localizado em Duisburg Nord, na Alemanha. Com uma área de aproximadamente 180 hectares, o parque foi implantado no terreno de uma antiga fábrica de produção de carvão e aço, que foi abandonada em 1985, deixando o local significantemente poluído.

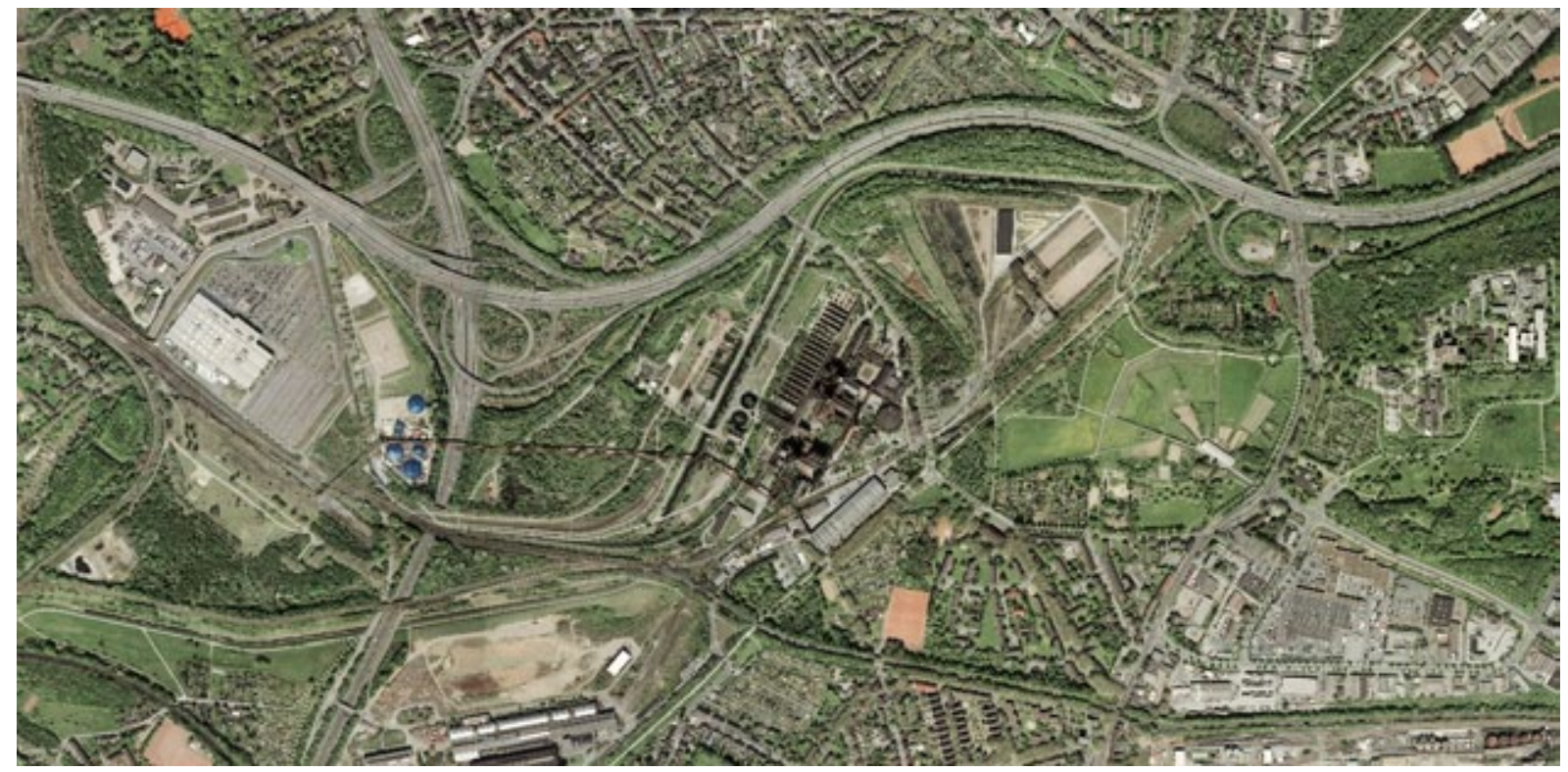

Figura 3 - Vista Aérea do Landschaftspark. Fonte: Google Earth 2015

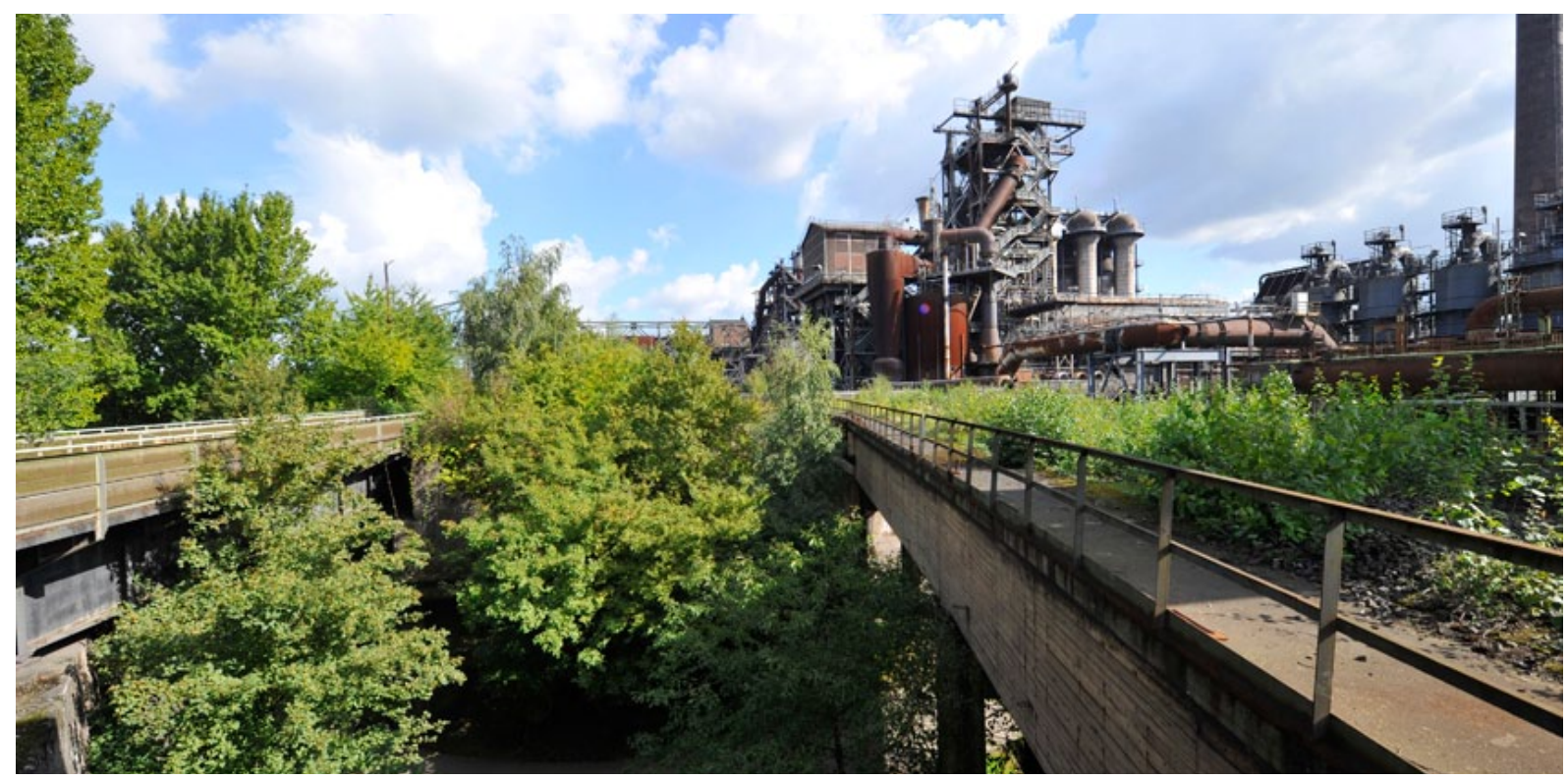

Figura 4 - Vista da Passarela do Parque

foto Thomas Berns fonte:http://en.landschaftspark.de/the-park 
O projeto concebido e desenhado por Latz + Partner (Peter Latz), assim como o Gas Works Park, busca compreender o passado industrial ao invés de rejeitá-lo e traz um novo olhar para a questão dos processos naturais aplicados aos projetos de recuperação de áreas contaminadas.

A implantação do parque durou de 1990 até 2002 e as estratégias de projeto para recuperação da área foram baseadas na restauração de processos naturais em um ambiente de devastação e distorção. Dentre esses processos, vale ressaltar o programa de bioremediação de solo contaminado, o uso de processos naturais de erosão para entrelaçar estruturas fabris obsoletas com a paisagem, o uso da vegetação espontânea para composição do paisagismo e o tratamento de escoamento superficial da chuva em leitos de sedimentação vegetados.

O projeto é um exemplo ilustrativo das teorias da terceira paisagem, sendo sua proposta de paisagismo inovadora ao abrigar a vegetação espontânea, indo de encontro aos preceitos do Desenho Ambiental, por ir além da função estética da vegetação, com uma solução que exige baixa manutenção e se equilibra com a formação natural do território.

O parque vem contribuir, ainda, para a rede de parques e áreas verdes da cidade, onde a vegetação tem presença marcante, sendo difícil o reconhecimento dos limites do parque pela observação da foto aérea.

Outro fator relevante do projeto foi a incorporação de estruturas obsoletas que normalmente seriam demolidas e descartadas, gerando uma grande de quantidade de resíduos. No caso, este fato foi evitado e é justamente nessas estruturas obsoletas que acontece grande parte do programa proposto para o parque, proporcionando uma experiência distinta aos visitantes e estimulando a sensibilização sobre nossa relação com as estruturas que construímos e abandonamos.

\section{PROMENADE PLANTÉ}

O Coulée verte René-Dumont ou Promenade Plantée é um parque público com 4,7 km de extensão e aproximadamente 6,5 hectares, construído sobre uma infra-estrutura ferroviária obsoleta no $12^{\circ}$ arrondissement de Paris. O viaduto foi construído em 1859 e abandonado em 1969, se tornando objeto de estudo do master plan de Jacques Vergely e Philippe Mathieu em 1988, sendo o parque inaugurado em 1993. 


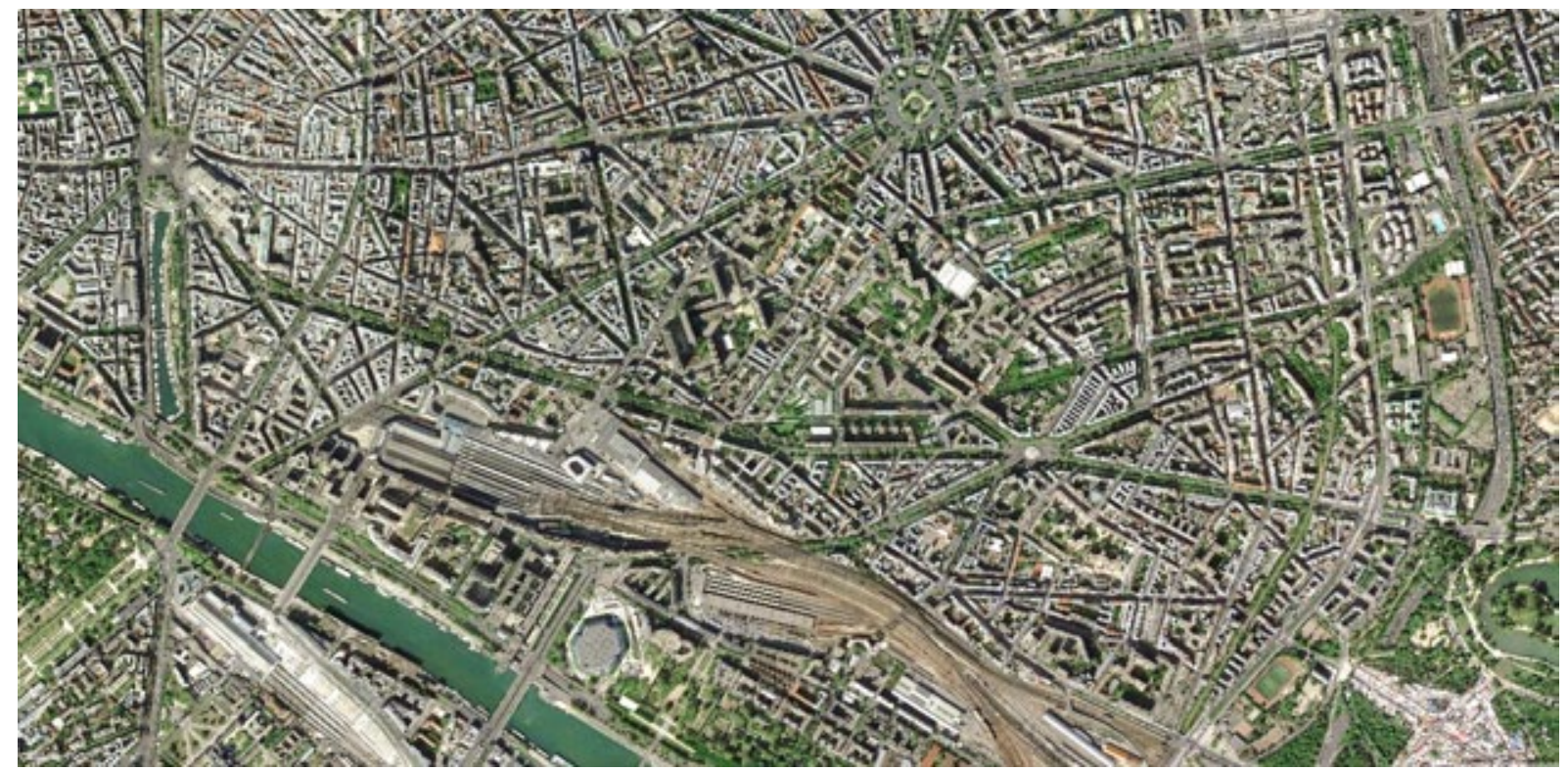

Figura 5 - Vista Aérea do Promenade Planté. Fonte: Google Earth 2015

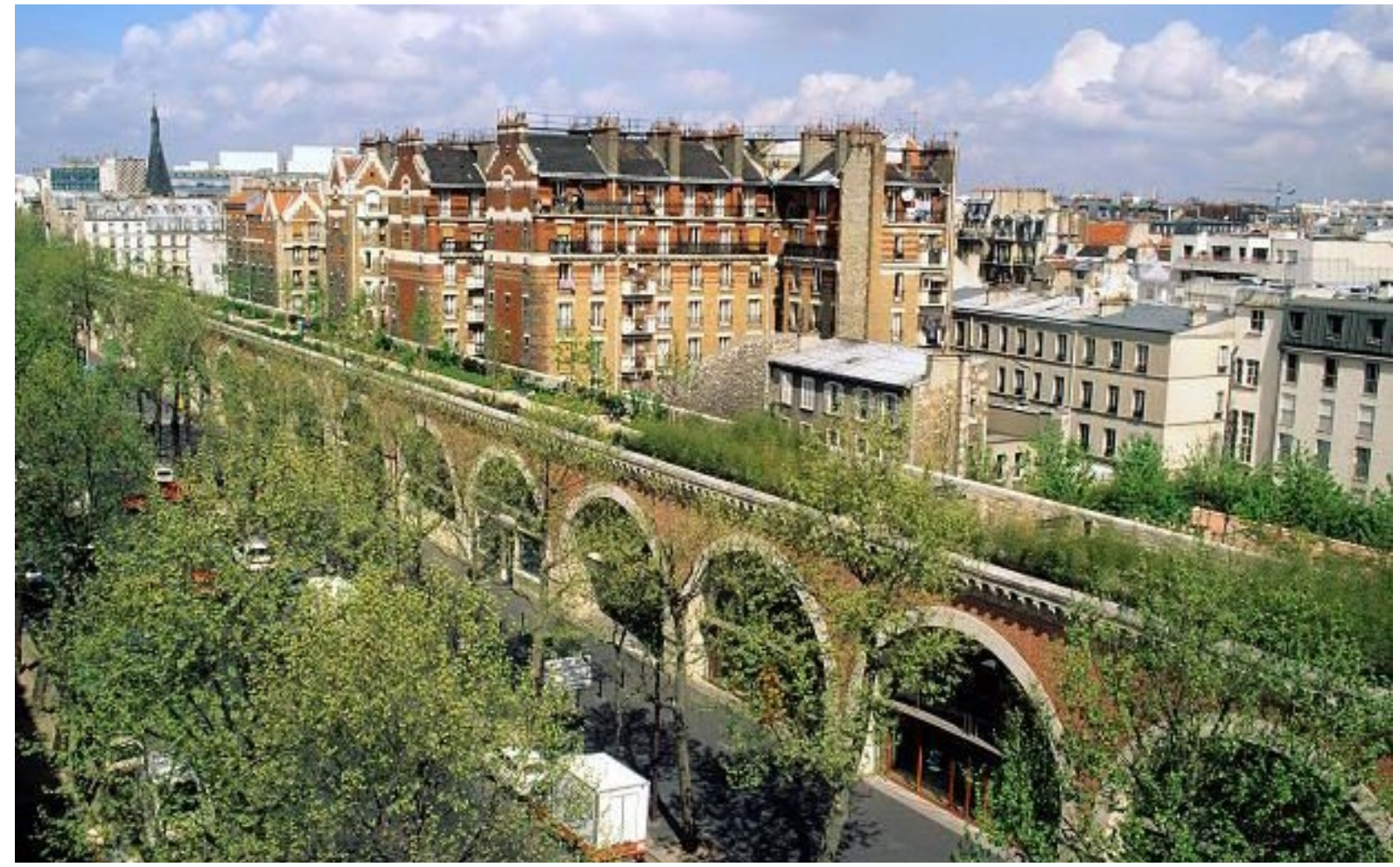

Figura 6 - Vista dos arcos do Promenade Planté. Fonte:www.likealocalguide.com

A proposta foi inovadora ao romper as delimitações convencionais de um parque e se entremear pela malha urbana, cortando 20 quadras e dois prédios, abrindo acessos por jardins verdes, além de trazer novos programas, como lojas e restaurantes, para 
os antigos arcos do viaduto, que se encontravam abandonados, causando insegurança aos transeuntes.

O parque não só trouxe mais verde para esta região da cidade, como também estimulou a revitalização de diversos edifícios abandonados no seu trajeto. O parque é uma provocação à relação entre estruturas abandonadas, a malha urbana circundante e a biodiversidade, promovendo uma experiência incomum da paisagem urbana.

\section{HIGH LINE PARK}

O High Line Park é um parque instalado sobre uma antiga ferrovia em Manhattan, na cidade de Nova lorque. O projeto, com 2,3 quilômetros e aproximadamente 2,4 hectares, é fruto de uma parceria público privada entre a prefeitura da cidade de Nova lorque e a associação Friends of the High Line. A concepção ficou a cargo do consórcio entre James Corner Field Operations, Diller Scofidio +Renfro, e Piet Oudolf.

A ferrovia foi construída na década de 1930 e era usada para o transporte de carnes e aves. Com a chegada das rodovias, o uso da ferrovia foi diminuindo até ser desativada em 1980. Em 2006 começou a construção da primeira etapa de implantação, sendo esta inaugurada em 2009. A terceira e última etapa foi concluída e aberta ao público em 2014.

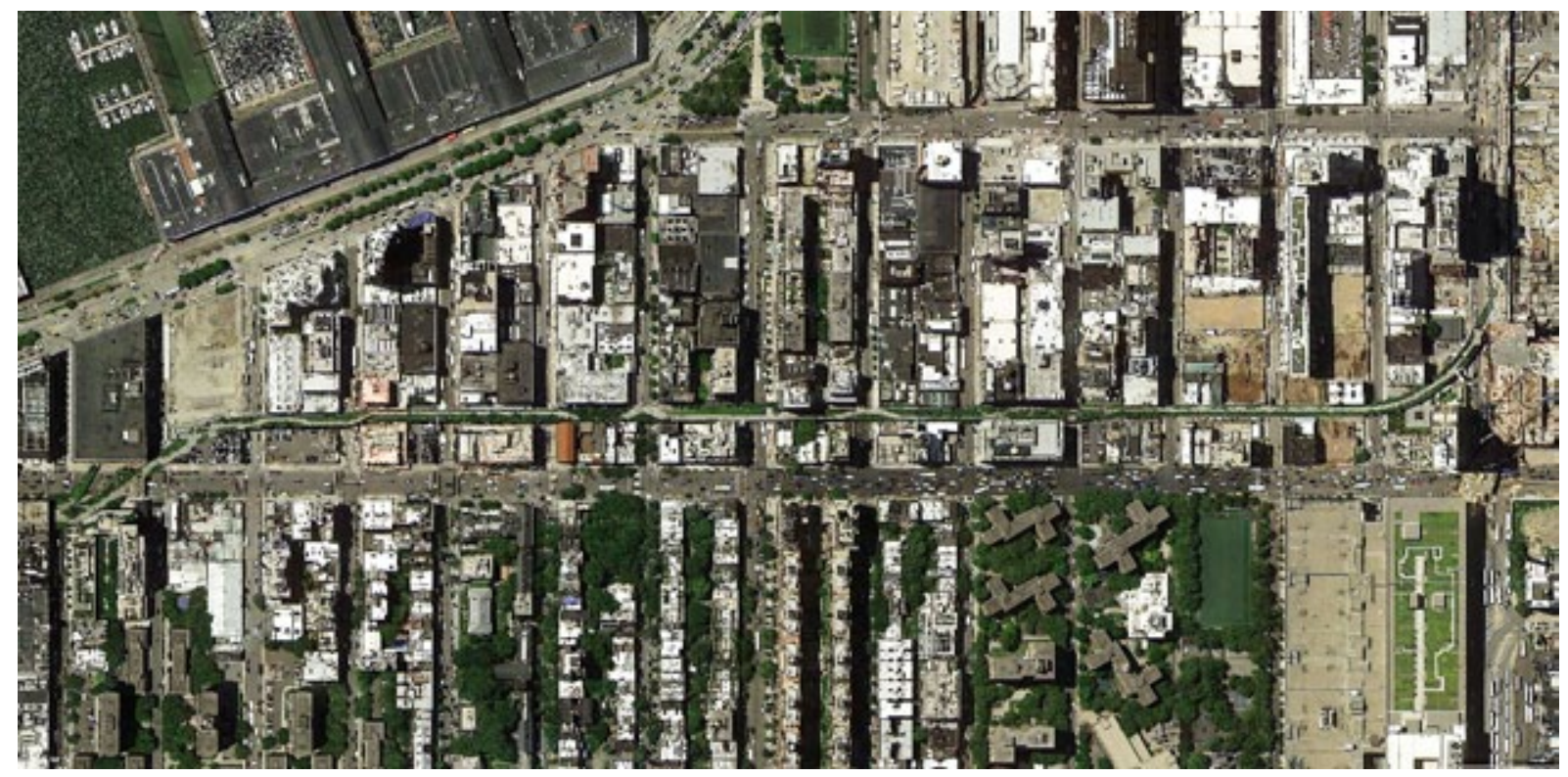

Figura 7 - Vista Aérea do High Line Park. Fonte: Google Earth 2015 


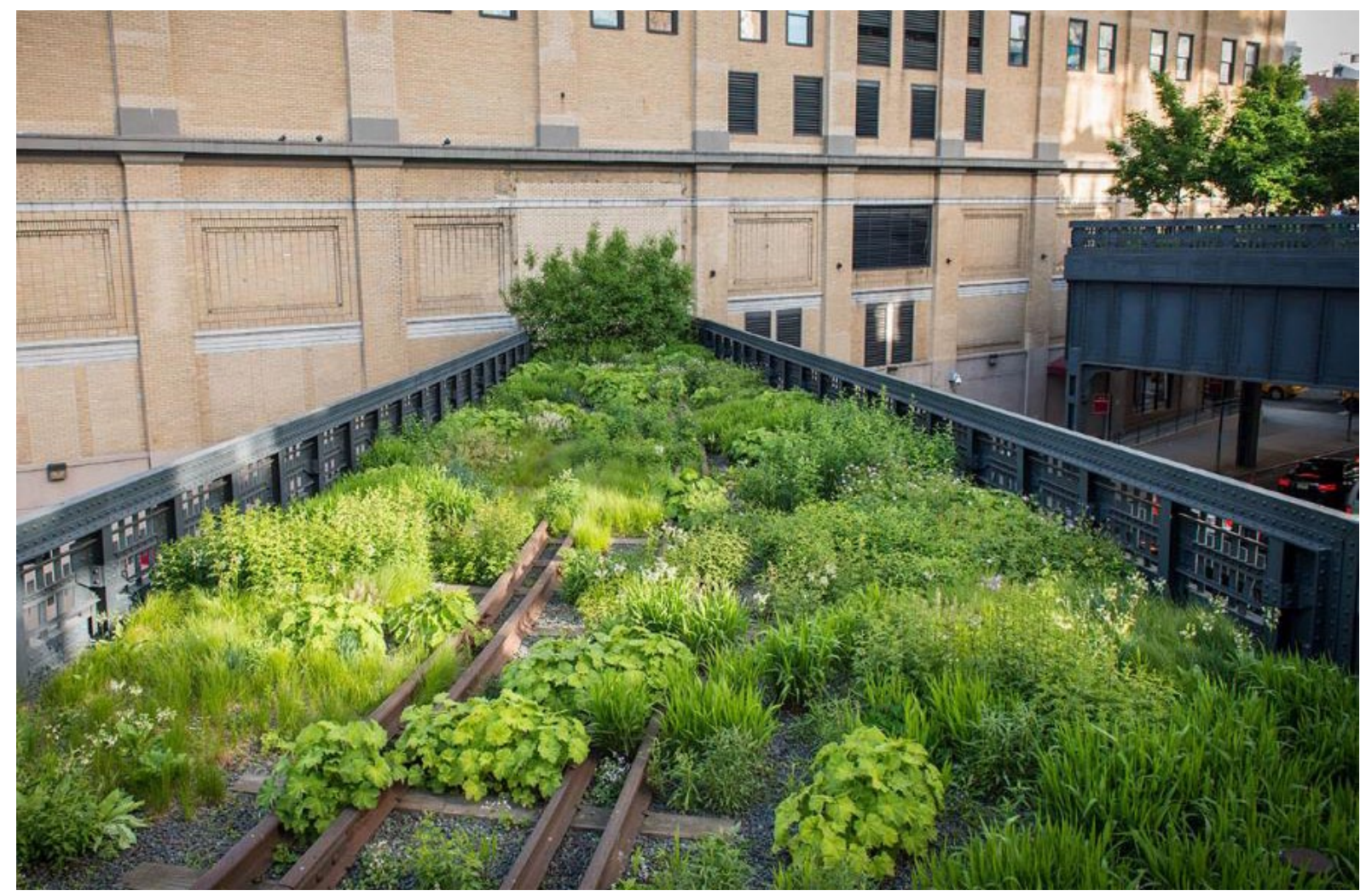

Figura 8 - Jardim elevado sobre a ferrovia. Fonte: http://www.thehighline.org

Um destaque do projeto é o paisagismo, que teve o plantio inspirado na paisagem auto semeada que cresceu nos trilhos elevados durante os 25 anos depois que os trens pararam de correr. As espécies de plantas perenes, ervas, arbustos e árvores foram escolhidas pela sua rusticidade, sustentabilidade, textura e variação de cor, com foco em espécies nativas. Muitas das espécies que originalmente cresceram no leito ferroviário do High Line foram incorporados à paisagem do parque diminuindo a necessidade de manutenção e melhor enquadramento com a biodiversidade que habita o local.

Assim como Promenade Plantée, o Highline é um parque que explora uma relação distinta com a natureza e a biodiversidade de áreas densamente ocupadas, em regiões onde a formação de redes de áreas verdes é inviabilizada pela escassez de áreas livres.

Aqui a teoria da terceira paisagem pode ser observada, assim como a provocação de novas relações com o meio natural vinculado a estruturas construídas pelo homem e que negam as relações naturais com o território. 
Estes dois projetos são extremamente importantes para discussões sobre desenho ambiental, ficando a questão: será possível uma leitura ambiental de áreas extremamente antropomorfizadas?

\section{STRATFORD OLYMPIC PARK}

O Stratford Olympic Park ou Queen Elizabeth Olympic Park foi concebido pelo consórcio EDAW, composto pelos escritórios EDAW and Buro Happold, Arup e WS Atkins. O complexo foi construído para abrigar as Olímpiadas de 2012, na cidade de Londres.

O parque foi construído em um terreno pantanoso de aproximadamente 45 hectares e sendo frequentemente drenado desde a era medieval. Foi usado como aterro para o entulho de prédios bombardeados durante a Segunda Guerra Mundial. O território era formado por um misto de áreas verdes e brownfields.

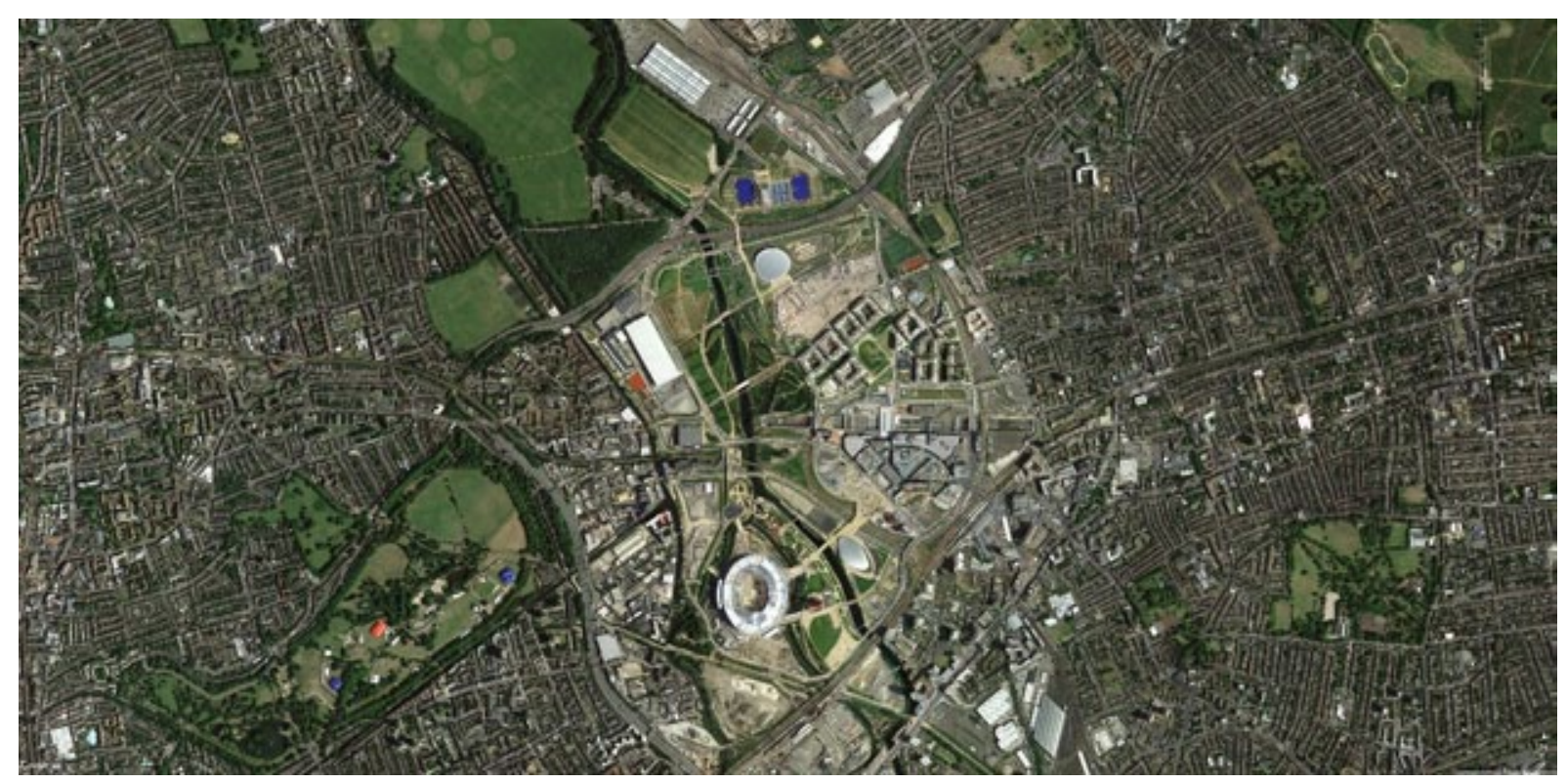

Figura 9 - Vista Aérea do Stratford Olympic ParkFonte: Google Earth 2015 


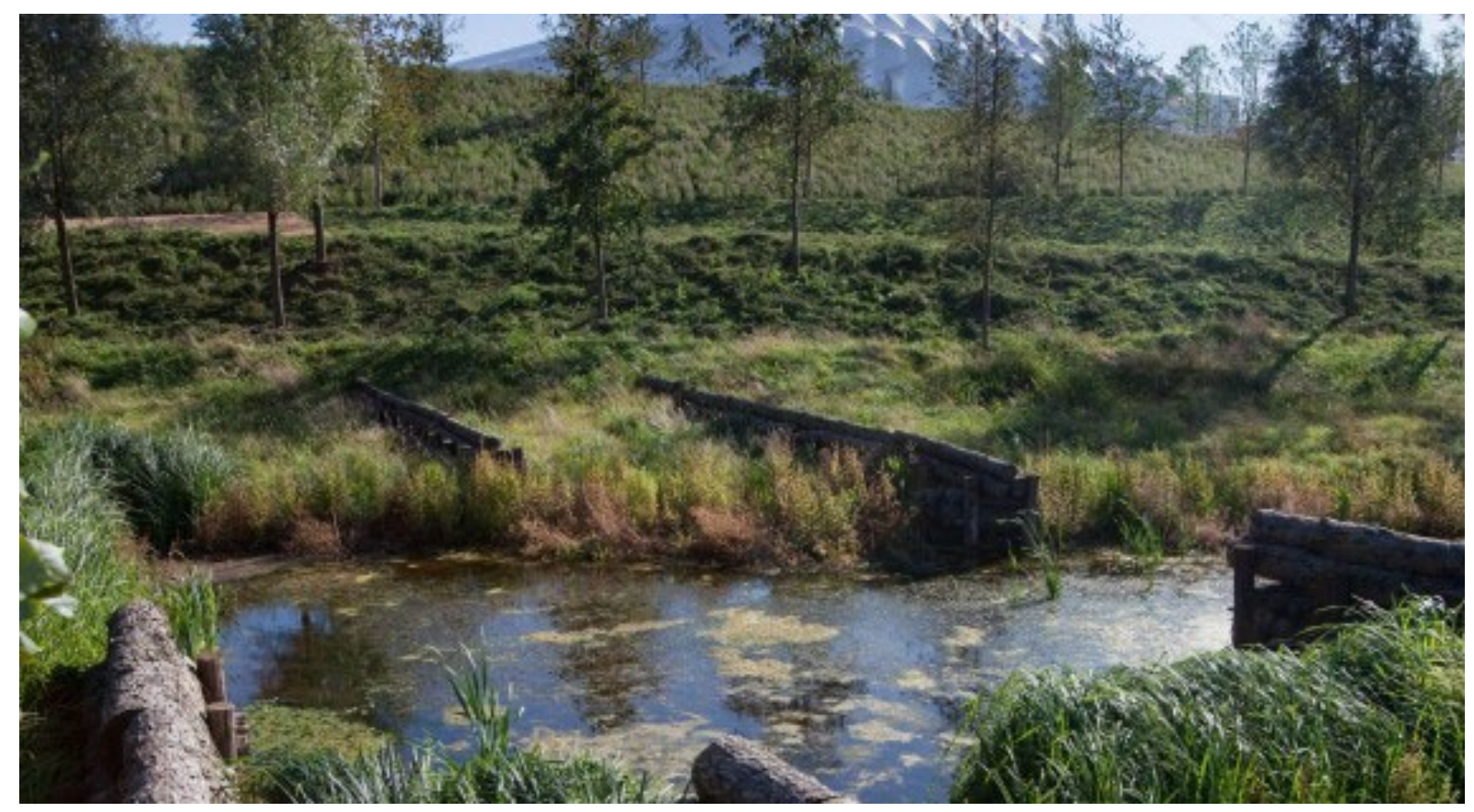

Figura 10 - Área renaturalizada dos canais que cortam o Parque fonte: http://queenelizabetholympicpark.co.uk/

O parque tem uma grande diversidade de usos, contando com universidades, apartamentos residenciais e museus. Além disso é um dos maiores parques urbanos criados na Europa, com o intuito de enriquecer a ecologia local, restaurando habitats de zonas úmidas e estimulando a horticultura urbana.

Segundo os autores do projeto, Robert Holden e Tom Turner, o ponto fundamental foi o planejamento da paisagem do local, mais do que o projeto de uma nova paisagem. O parque é um exemplar da aplicação das teorias do desenho ambiental na escala de uma grande metrópole, explorando a reconstituição de um ecossistema em áreas abandonadas e afetadas pela ação humana, atraindo para região uma população que antes a renegaria.

\section{ESCALA LOCAL: Estudos de caso na cidade de São Paulo}

No caso de São Paulo, com a diminuição do ritmo de industrialização da cidade a partir da década de 1960, deu-se início à migração da indústria para o interior paulistano. Este processo deixou como legado vastos Terrain Vagues, localizados principalmente nos arredores das várzeas dos rios. 
A recuperação destas áreas é alavancada predominantemente pelo setor privado. Segundo Vasques (2009), o setor imobiliário tem evidenciado a refuncionalização e esta se configura de forma setorial: na zona leste (Brás, Belém, Mooca, Tatuapé), antigas fábricas têm sido demolidas para dar lugar a empreendimentos residenciais; na zona sul (Vila Olimpia e proximidades da marginal Pinheiros), o interesse é a reconversão destes espaços obsoletos para novas empresas de tecnologias, centros comerciais e escritórios de alto padrão; na zona oeste (Água Branca, Barra Funda, Lapa, Jaguaré, Vila Leopoldina), a mudança se dá pela concentração de escritórios.

Mesmo com a predominância de empreendimentos privados, pode-se identificar alguns projetos urbanos com características que remetem aos conceitos e problemáticas apresentados neste artigo. A metodologia aplicada aos projetos nacionais foi a mesma utilizada nos projetos internacionais. São eles:

\begin{tabular}{l|l|c} 
Projeto & Autor & Ano \\
\hline Parque Villa Lobos & Decio Tozzi & 1994 \\
\hline Praça Victor Cívita & $\begin{array}{l}\text { Levisky Arquitetos Associados e Anna Julia } \\
\text { Dietzsch }\end{array}$ & 2008 \\
\hline Parque Orlando Villas Bôas & $\begin{array}{l}\text { André Graziano (coordenador de áreas verdes } \\
\text { da Prefeitura de São Paulo) }\end{array}$ & 2010 \\
\hline
\end{tabular}

\section{PARQUE VILLA LOBOS}

O projeto do parque de 73,2 hectares foi elaborado pelo arquiteto Décio Tozzi e está localizado no bairro de Pinheiros, na cidade de São Paulo.

Até 1989 o terreno abrigava um depósito de resíduos da Companhia de Entrepostos e Armazéns Gerais do Estado de São Paulo (CEAGESP) na sua porção oeste, na porção leste era depositado material dragado do Rio Pinheiros e na porção central funcionava um depósito de entulho da construção civil.

A partir de 1989 o parque Villa-Lobos começou a ser implantado, sendo aberto ao público em 1994. Atualmente o parque está sob a administração da Secretaria do Meio Ambiente do Estado de São Paulo (SMA). 


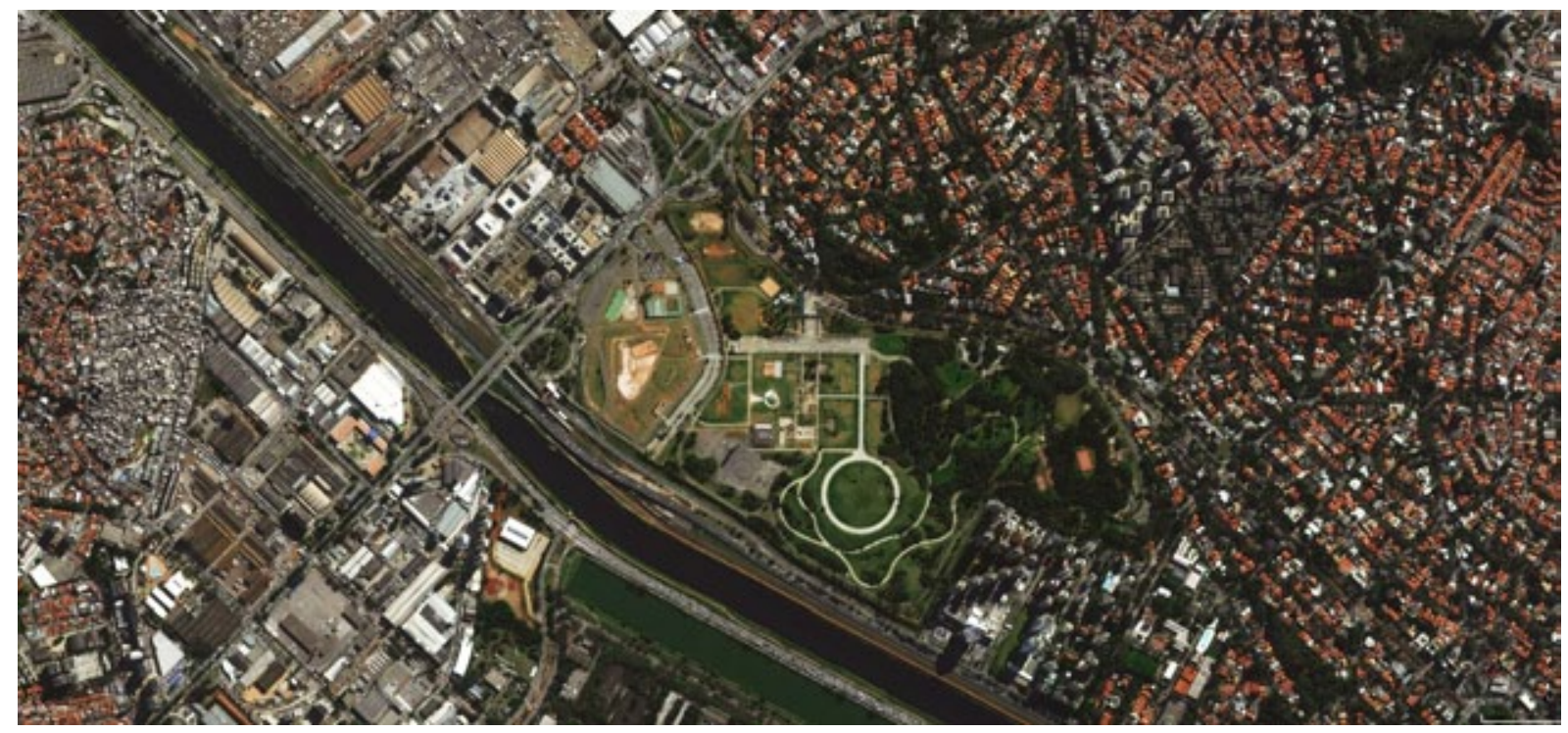

Figura 11 - Vista Aérea do Parque Villa Lobos. Fonte: Google Earth 2015

Como processo de preparação do terreno, foram retirados do local $500 \mathrm{mil} \mathrm{m}^{3}$ de entulho e movimentados 2 milhões de $\mathrm{m}^{3}$ de entulho e terra para acerto das elevações existentes. $O$ córrego Boaçava, que passa pela área, foi canalizado.

Este tipo de tratamento não garante a descontaminação do solo. Se o parque Villa-Lobos fosse construído atualmente, não poderia ser aberto ao público. A Cetesb exige, de áreas públicas e privadas, estudos preliminares e detalhados, além de um plano de intervenção para dar aval a áreas com suspeita de contaminação.

Em 2007, a Cetesb realizou uma análise preliminar na área e foram constatados problemas na água e subsolo, além de pontos de metano, dado que o terreno recebia material dragado do Rio Pinheiros. Contudo, o Parque não foi interditado, pois foi constatado que a contaminação não causaria danos aos usuários.

O projeto do Parque foi proposto depois da implantação do Landschaftspark, mas a abordagem é bem mais rasa do que naquele caso. A problemática de áreas contaminadas não foi explorada e a possibilidade de uma leitura ambiental do território não foi considerada. Como observa-se na foto aérea, o parque está situado nas proximidades da várzea do Rio Pinheiros, mas as potencialidades das dinâmicas naturais do local não são exploradas.

Contudo, o parque atrai um grande público que busca equipamentos de lazer para caminhadas, andar de bicicleta, patins e esportes de quadra. 


\section{PRAÇA VICTOR CIVITA}

A Praça foi implantada num terreno de 1,36 hectares onde funcionou, até a década de 1980, o Incinerador Pinheiros, também conhecido como Sumidouro, onde eram processados resíduos domiciliares e hospitalares. Depois, passou a ser ocupada por três cooperativas que faziam a triagem de materiais recicláveis e recebia cerca de $200 t$ de resíduos diariamente.

A iniciativa de recuperação do local foi fruto de uma parceria privada entre a Prefeitura de São Paulo e a Editora Abril. O projeto é de autoria das arquitetas Adriana Blay Levisky e Anna Julia Dietzsch e teve início em 2006.

A praça oferece programação cultural, esportiva e de educação ambiental. Abriga o Museu da Sustentabilidade e o Centro de Integração, Informação e Preparação para o Envelhecimento (CIIPE), além de uma arena coberta para shows, espaços para prática esportiva e áreas para convivência. Sua administração é de responsabilidade da Associação Amigos da Praça Victor Civita.

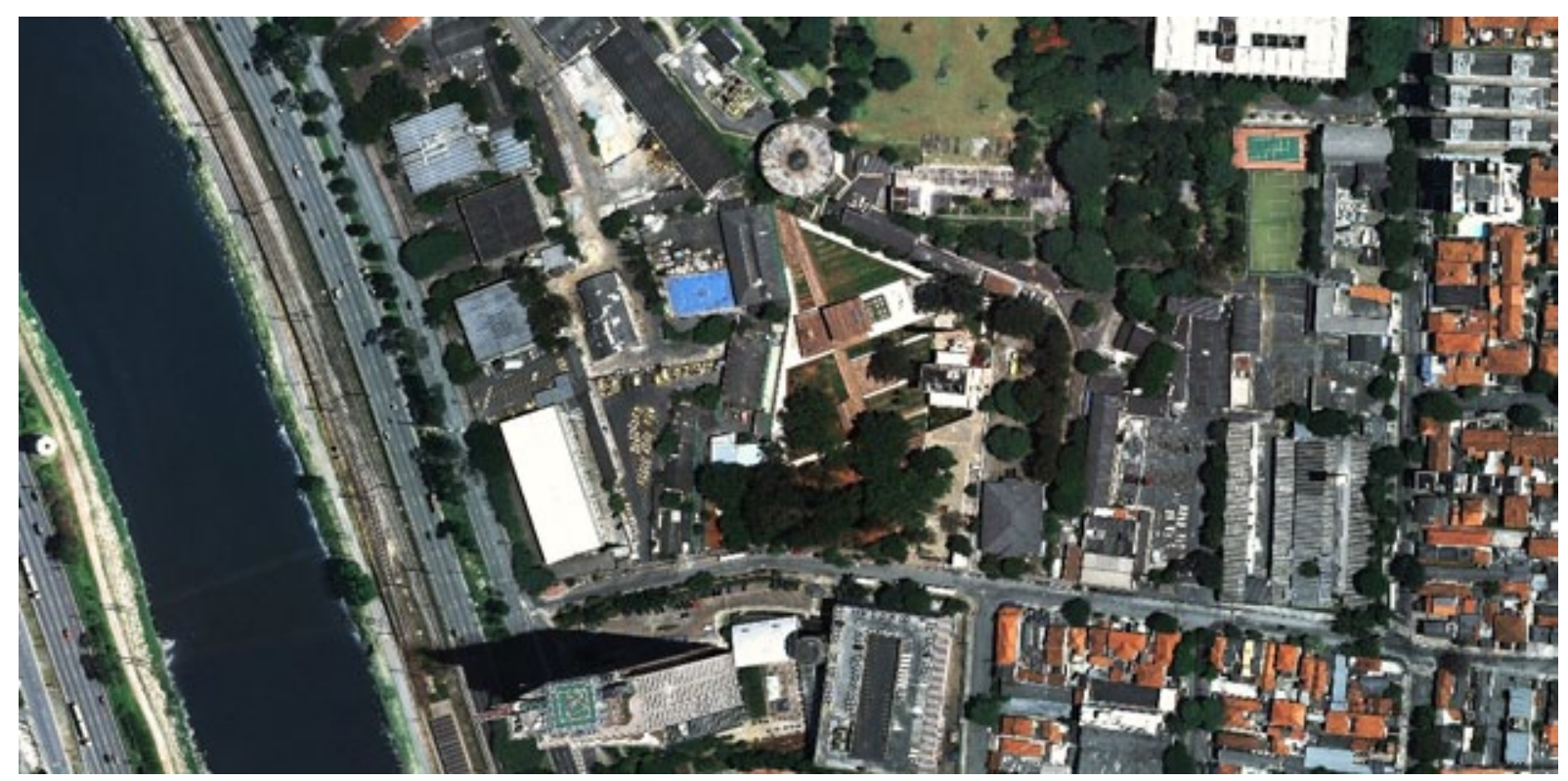

Figura 12 - Vista Aérea da Praça Victor Cívita. Fonte: Google Earth 2015 


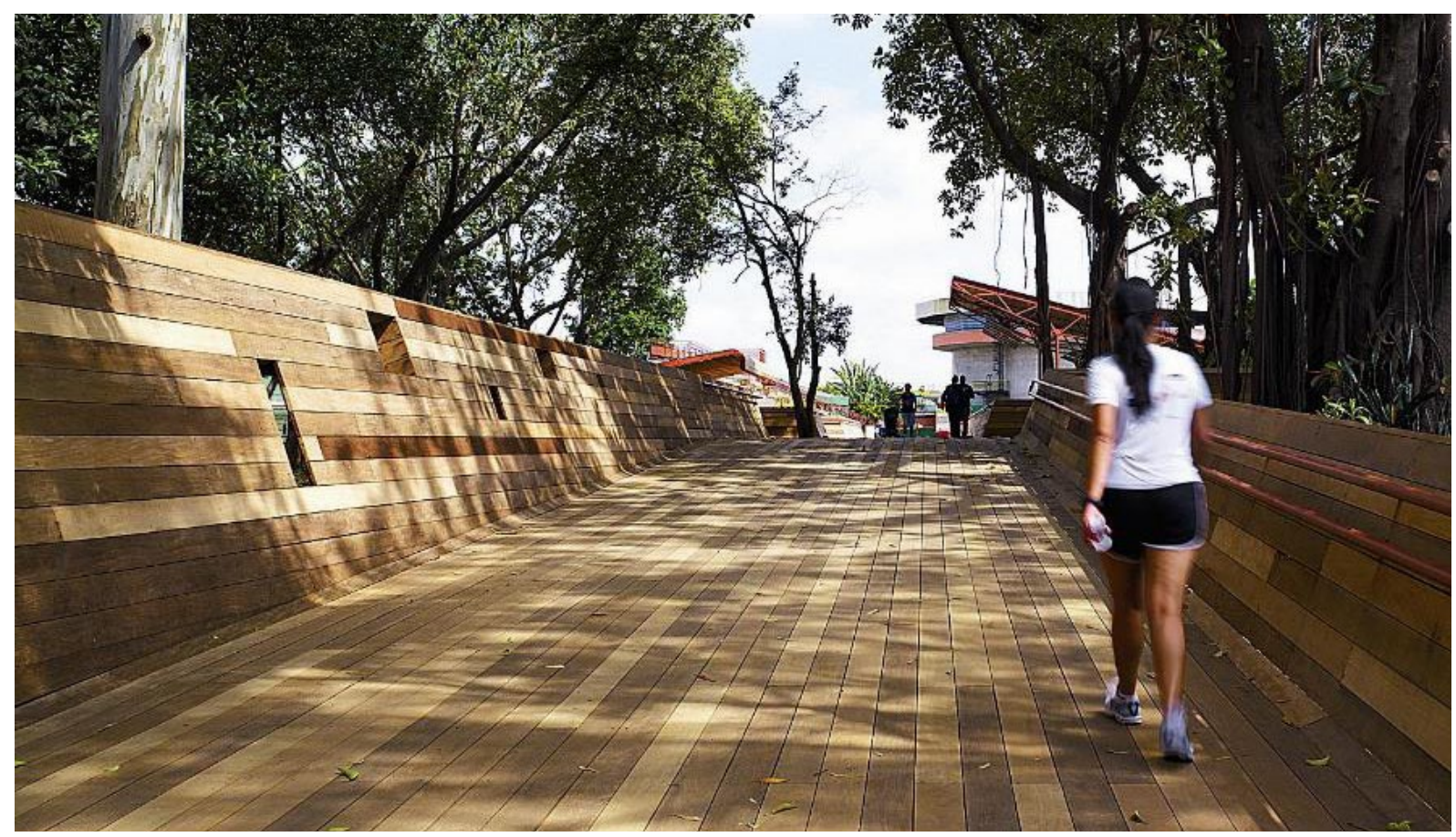

Figura 13 - Vista da rampa de acesso à praça. Foto: Nelson Kon

A temática da praça é a sustentabilidade, sendo explorada como propaganda do projeto. Contudo, os métodos para lidar com a contaminação do solo foram conservadores e nos pontos mais contaminados foi feita a contenção do solo e acrescida uma camada de $50 \mathrm{~cm}$ de solo para receber o plantio. Para evitar o contato dos usuários com o solo foram instalados decks elevados por toda a praça.

Neste caso, as possibilidades de uma maior interação com as dinâmicas naturais do terreno também foram pouco exploradas. A área de implantação do parque é vizinha de áreas livres, mas sua interação é baixa, não fazendo uso de possibilidade de contribuição para a biodiversidade de área como um todo.

\section{LEOPOLDINA ORLANDO VILLAS BÔAS}

O Parque Olando Villas Bôas foi resultado de uma parceria entre a Prefeitura e o Governo do Estado. A primeira fase do parque, com aproximadamente 5,5 hectares, foi entregue em janeiro de 2010, mas, por problemas de contaminação foi interditado em março de 2015. 
O parque está localizado na subprefeitura da Lapa em uma área de 5,5 hectares, onde funcionou por trinta anos uma unidade de tratamento de esgoto da Sabesp.

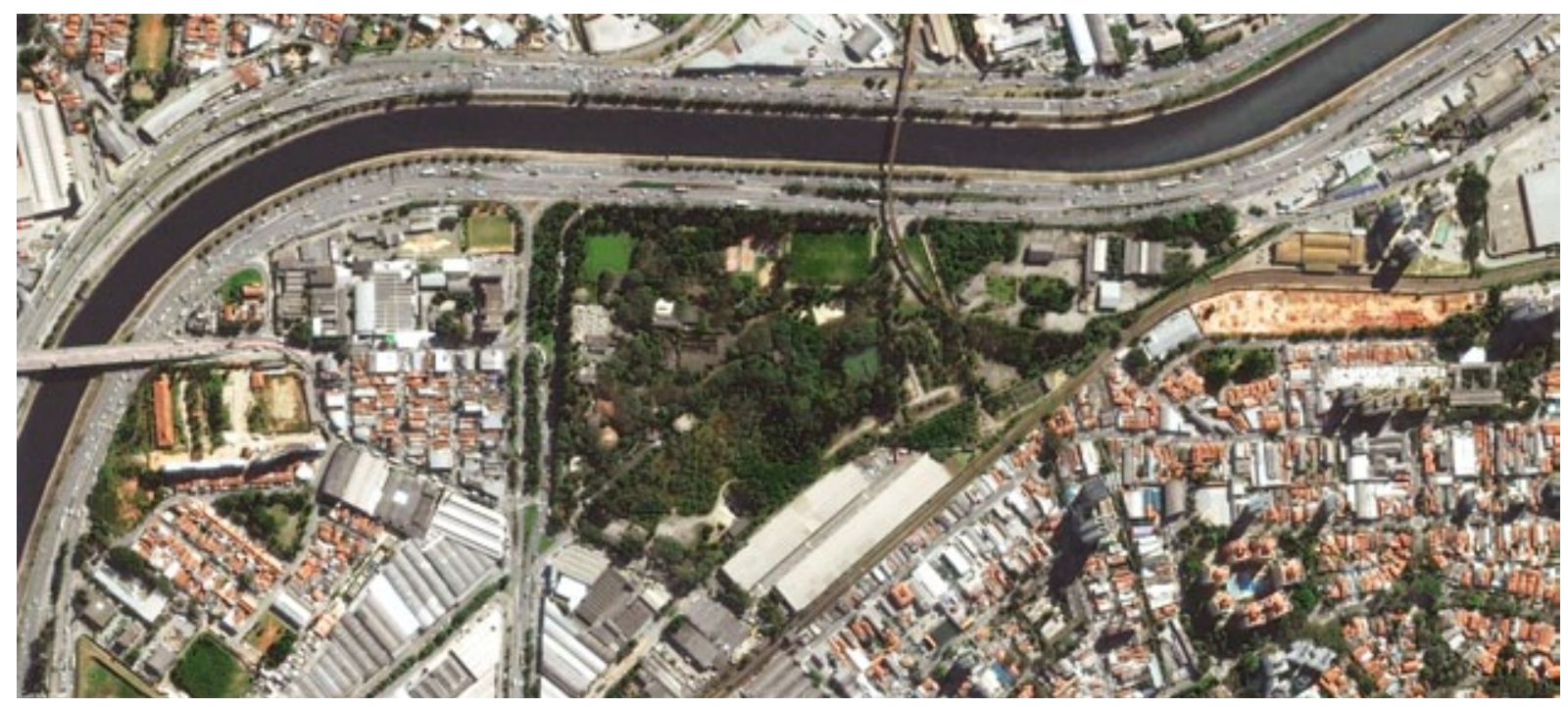

Figura 14 - Vista Aérea do Parque Orlando Villas Bôas. Fonte: Google Earth 2015

O pedido de fechamento foi feito pelo Ministério Público de São Paulo em 2012. No processo do Ministério Público, o promotor diz que duas pessoas passaram mal - tiveram tontura, diarréia e dor de estômago - depois jogar futebol no local.

O Parque é um exemplo claro que áreas contaminadas devem receber tratamento especial e que apenas a manutenção do verde não é suficiente para tornar o local seguro para frequentação.

\section{CONCLUSÕES: as potencialidades do desenho ambiental}

Este artigo considera a importância dos brownfields como um campo a ser explorado por novos projetos, que deverão reconhecer estes territórios como áreas abertas a novas interpretações de novos momentos da urbanidade.

Estas áreas guardam potencial para ocupação e podem ser a base para um recomeço, uma oportunidade para experimentar novos processos e questionar a relação entre o homem e o meio que ele habita, como preconiza o Desenho Ambiental. Deve-se 
destacar que essa mudança de paradigma exige uma nova complexidade de projetos que exploram novos instrumentos e processos.

Dentro destes preceitos, arquitetos urbanistas têm papel de estimular novas formas de tratar este tipo de problemática, buscando entender a importância de uma visão sistêmica, onde ciclos biológicos estão intimamente ligados à concepção do projeto.

Os exemplos globais, indicados anteriormente, postos em ordem cronológica mostram uma evolução da relação dos parques com o território e com a população que faz uso deste espaço. Desde 1975, quando foi implantado o Gas Works Park, pode-se perceber uma clara evolução das propostas para os parques, tanto para a vegetação quanto para os usos e relação com as estruturas produzidas pelo homem.

O Gas Works Park, portanto, dá início a uma abordagem relacionada aos conceitos de desenho ambiental, ao explorar as potencialidades de um brownfield, através da não eliminação das estruturas que compunham a paisagem local, além de possibilitar a recuperação do solo contaminado por processos biológicos.

Em uma sequência cronológica, o Landschaftspark, além das iniciativas apresentadas pelo Gas Works Park, também traz uma visão de projeto que remete aos conceitos da Terceira Paisagem, ao se utilizar da vegetação espontânea, que cresceu no local para compor o paisagismo, e explora os processos naturais na degradação das estruturas demolidas que compõe a paisagem do parque. Ele contribui para biodiversidade do local em um sistema de áreas verdes intrinsicamente ligado às dinâmicas naturais do território e servindo como modelo de sensibilização ao não renegar estruturas que estariam fadadas ao descarte, expondo possibilidades de como repensar nossa relação com os resíduos que geramos.

Já os parques Promenade Planté e High Line, assim como nos exemplos anteriores, trazem um novo olhar para estruturas obsoletas. No entanto, extrapolam o conceito de parque ao potencializar os Terrain Vagues localizados estrategicamente na malha urbana e interagem diretamente com as edificações do entorno, articulando os espaços livres do tecido da cidade. São propostas que levam a outro patamar a discussão sobre o desenho ambiental em áreas urbanas densamente ocupadas.

Como exemplo mais recente, o Parque Stratford Olympic Park se mostra como o projeto que incorpora as soluções utilizadas nos projetos anteriores e avança no sentido 
de buscar maior complexidade em relação aos processos naturais, seguindo diversas diretrizes do Desenho Ambiental. Privilegia a retomada de processos naturais e explora os processos de conservação de energia, entendendo o parque como um sistema complexo articulado com processos naturais e integrado à cidade. O parque é um exemplo de como é possível reconectar os habitantes da cidade com a natureza e a biodiversidade, ao propor um programa diversificado em uma proposta paisagística que explora as relações naturais do terreno.

Em comparação aos exemplos internacionais, os parques implantados em brownfields localizados em São Paulo mostram abordagens superadas quanto ao tratamento das áreas contaminadas e em relação aos usos propostos.

No parque Villa Lobos, durante seu projeto e execução, não foram considerados os impactos de remoção de entulho e terraplenagem do terreno. O projeto propõe uma série de usos e atividades sobre solos e lençol freático contaminados e córregos canalizados. Percebe-se, assim, que o parque não apresenta uma relação sistêmica em relação aos processos naturais que ocorrem no local, sem explorar o potencial da terceira paisagem.

Já na praça Victor Civita, observa-se que a descontaminação do solo e manejo de passivos ambientais são tratados como elemento de propaganda. Dada a temática da praça, métodos mais inovadores e voltados ao desenho ambiental poderiam ter sido explorados, como por exemplo a fitoremediação, garantindo maior contato dos visitantes com o meio natural e manutenção menos dispendiosa.

O parque Orlando Villas Bôas é um caso claro da falta de articulação com os princípios do Desenho Ambiental. O projeto propõe um paisagismo cênico, no qual os processos de recuperação das áreas contaminadas não foram explorados, levando ao fechamento do parque. A importância da área como potencial na construção da paisagem foi ignorada, em um projeto que não traz à tona as potencialidades do Terrain Vague que constitui a área.

Em vista dos projetos analisados e da observação dos processos utilizados em cada um deles, conclui-se que os projetos desenvolvidos em São Paulo estão em um estágio muito atrasado em comparação com os exemplos globais, em relação à aplicação de novas técnicas, estratégias e estéticas, que ainda são pouco exploradas. Em uma análise dos conceitos apresentados, que buscam a eficiência de processos antrópi- 
cos em harmonia com os processos naturais, percebe-se uma falta de aplicação nos projetos nacionais. No caso do conceito de brownfields, não há uma visão sistêmica em relação às áreas contaminadas, sendo que o tratamento é focado na solução do problema no local e as consequências das soluções adotadas, mesmo em casos onde o resíduo é destinado a local adequado, não levam em consideração todos os impactos que estes resíduos acarretam no ambiente como um todo. No caso da praça Victor Civita, por exemplo, o solo contaminado foi apenas transferido para um aterro, gerando um passivo ambiental em outro local, ao invés de ser tratado localmente.

Nos termos de Terrain Vague, destaca-se a preservação, na praça Victor Civita, do incinerador existente, que remete ao cenário do passado, articulando o novo projeto com a memória do local. Iniciativa semelhante não pode ser observada nos outros dois projetos em São Paulo, este tipo de apropriação além de marcar as memórias do local, colabora com a redução da produção de entulho.

Quanto ao conceito de Terceira Paisagem, percebe-se que em todos os casos, o paisagismo, mesmo fazendo uso de espécies nativas, não explora a potencialidade da vegetação espontânea, sendo comum a solução de propostas de paisagem que dependem de manutenção contínua, e não potencializam a biodiversidade local de forma plena.

Diante das condições de comparação apresentadas e do visível atraso do Brasil no tratamento paisagístico de áreas abandonadas e contaminadas, percebe-se que é necessária a mudança de paradigmas projetuais no país, através da aplicação dos princípios de Desenho Ambiental. É importante, portanto, que exista uma abertura à novas experimentações que deverão propor uma nova forma de relação entre o meio antrópico e o meio natural, traçando caminhos adequados à nossa realidade $\mathrm{e}$ desejos em concordância com os sistemas naturais, exigindo a aceitação de novos padrões estéticos e a sensibilização do público perante novas formas de lazer e contemplação da paisagem. 


\section{BIBLIOGRAFIA}

DONADON, Edilene Teresinha. "Terrain Vagues": Um estudo das áreas urbanas degradadas, baldias ou derrelitas em Campinas. 2009. 184 f. Dissertação (Mestrado) - Curso de Arquitetura e Construção, Faculdade de Engenharia Civil, Arquitetura e Urbanismo, Unicamp, Campinas, 2009.

FRANCO, Maria de Assunção Ribeiro. Desenho Ambiental: Uma Introdução à Arquitetura da Paisagem com o Paradigma Ecológico. 3. ed. São Paulo: Annablume, 2000. 224 p.

HOUGH, Michael. Cities and natural process. Londres: Routledge, 1995. 326 p.

QUEIROGA, Eugenio Fernandes. A megalópole e a praça: O espaço entre a razão de dominação e a ação comunicativa. 2001. 351 f. Tese (Doutorado) - Curso de Arquitetura, Faculdade de Arquitetura e Urbanismo, Universidade de São Paulo, São Paulo, 2001.

MCHARG, lan. Design With Nature. 2. ed. New York: Natural History Press, 1994.

SANTOS, Milton. Pensando o espaço do homem. 5. ed. São Paulo: Editora da Universidade de São Paulo, 2012.

Por uma outra globalização. 6a São Paulo: Record, 2001.

SOLÀ-MORALES, Iganasi de. Territorios. Barcelona: Gustavo Gili, 2002.

VASQUES, Amanda Ramalho. Refuncionalização de Brownfields: Estudo de caso na Zona Leste de São Paulo. 2005. 160 f. Dissertação (Mestrado) - Departamento de Igce, Unesp, Rio Claro, 2005.

\section{Sites Consultados}

ARCHDAILY. Praça Victor Civita / Levisky Arquitetos e Anna Julia Dietzsch. 2015. Disponível em: <http://www.archdaily.com.br/br/01-10294/praca-victor-civita-leviskyarquitetos-e-anna-julia-dietzsch>. Acesso em: 9 ago. 2015. 
CORPORATION, London Legacy Development. QUEEN ELIZABETH OLYMPIC PARK. 2015. Disponível em: <http://queenelizabetholympicpark.co.uk/>. Acesso em: 09 ago. 2015.

INSTITUTE, The Northeast-midwest. Oficial Page. 2015. Disponível em: < http://www. nemw.org/>. Acesso em: 25 set. 2015.

LINE, Friends Of The High. Oficial Page. 2015. Disponível em: < $\underline{\text { http: } / / w w w . t h e h i g h l i n e . ~}$ org/>. Acesso em: 09 ago. 2015

NOTTINGHAM, University Of. CABERNET. 2013. Disponível em: < http://www. cabernet.org.uk/index.asp?c=1124>. Acesso em: 20 set. 2015.

PARK, Landschaftspark Duisburg-nord. Oficial Page. 2015. Disponível em: < http:// www.landschaftspark.de/der-park>. Acesso em: 08 ago. 2015.

PARTNER, Latz +. Office Page. 2015. Disponível em: <http://www.latzundpartner.de/en/>. Acesso em: 08 ago. 2015.

PAULO, Folha de S.. Estado de SP avalia contaminação no subsolo do parque Villa Lobos. 2012. Disponível em: <http://www1.folha.uol.com.br/ cotidiano/2012/01/1037035-estado-de-sp-avalia-contaminacao-no-subsolo-doparque-villa-lobos.shtml>. Acesso em: 20 set. 2015.

SEATTLE, City Of. Seattle Parks and Recreation. 2015. Disponível em: < http://www. seattle.gov/parks/park_detail.asp?ID=293>. Acesso em: 18 set. 2015.

SMDU. Secretaria Municipal de Desenvolvimento Urbano. Disponível em: <http:// www.prefeitura.sp.gov.br/cidade/secretarias/desenvolvimento urbano/>. Acesso em: 10 jul. 2015.

SVMA. Secretaria Municipal do Verde e do Meio Ambiente: Parques. 2015. Disponível em: <http://www.prefeitura.sp.gov.br/cidade/secretarias/meio ambiente/ parques/>. Acesso em: 2 ago. 2015. 